新規非イオン性等浸透圧造影剂 iodixanol の

ラットおよびウサギにおける生殖発生毒性

藤川香津子, 坂口ゆかり, 原田 滋雄,

Eckart HOLTZ*, Janet A. SMITH ${ }^{* *}$, Ove SVENDSEN ${ }^{* * *}$

第一製薬株式会社 開発研究所 安全性研究センター

T134 東京都江戸川区北葛西 1 丁 目16-13

${ }^{*}$ Nycomed Imaging A. S., Imaging Research and Development Division,

Nycoveien 1-2, P. O. Box 4220 Torshov N-0401 Oslo, Norway

** Huntingdon Research Centre Ltd.,

Huntingdon, Cambridgeshire, PE 18 6ES, England

*** SCANTOX Biological Laboratory Ltd.

Hestehavevej 36A, Ejby DK-4623 Lille Skensved, Denmark

\title{
REPRODUCTIVE TOXICITY OF IODIXANOL, A NEW NON-IONIC, ISO-TONIC CONTRAST MEDIUM IN RATS AND RABBITS
}

\author{
Katsuko FUJIKAWA, Yukari SAKAGUCHI, Shigeo HARADA, \\ Eckart HOLTZ* ${ }^{*}$, Janet A. SMITH ${ }^{* *}$ and Ove SVENDSEN *** \\ Drug Safety Research Center, Developmental Research Laboratories, Daiichi Pharmaceutical Co., Ltd., \\ 16-13, Kita-Kasai 1-chome, Edogawa-ku, Tokyo 134, Japan \\ * Nycomed Imaging A.S., Imaging Research and Development Division \\ Nycoveien 1-2, P. O. Box 4220 Torshov N-0401 Oslo, Norway \\ ${ }^{* *}$ Huntingdon Research Centre Ltd. \\ Huntingdon, Cambridgeshire, PE18 6ES, England \\ ${ }^{* * *}$ SCANTOX Biological Laboratory Ltd. \\ Hestehavevej 36A, Ejby DK-4623 Lille Skensved, Denmark
}

(Received May 11, 1995 ; Accepted August 14, 1995)

\begin{abstract}
The reproductive toxicity of iodixanol, a non-ionic isotonic contrast medium, was investigated in rats and rabbits. Iodixanol was administered intravenously to male rats at doses of $0.3,1.0$ or $2.0 \mathrm{gI} / \mathrm{kg} /$ day for 80 days or more until successful copulation. Female rats were treated with iodixanol at the same dose levels for at least 14 days prior to and in the early stage of pregnancy. No remarkable adverse effects on fertility were noted at any dose level. Increased water consumption and swollen paws/face were observed among male rats receiving $>1.0 \mathrm{gI} / \mathrm{kg} /$
\end{abstract}

\footnotetext{
連絡先： ₹134 東京都江戸川区北葛西 1丁目16-3

第一製薬侏安全性研究センター

藤川香津子
} 
day. In addition, decreased food consumption was observed in males of the $2.0 \mathrm{gI} /$ $\mathrm{kg} /$ day group. In female rats, no remarkable adverse effects were noted at any dose level. Iodixanol elicited no evidence of teratogenicity when administered during the fetal organogenesis period to pregnant rats and rabbits at doses of $0.3,1.0$ or $2.0 \mathrm{gI} /$ $\mathrm{kg} /$ day. No remarkable changes were observed in rat or rabbit fetuses, nor in dams of any dose group. In a perinatal and postnatal dosing study in rats using doses of $0.3,1.0$ or $2.0 \mathrm{gI} / \mathrm{kg} /$ day, iodixanol did not adversely affect the reproductive performance of the treated parent animals and pre- and postnatal development of their offspring.

KEY WORDS : Iodixanol, Non-ionic isotonic contrast medium, Reproductive toxicity, Rat, Rabbit.

緒言

Iodixanol は，ノルウェーの Nycomed 社で開発さ れた二量体（ダイマ一型）の化学構造を有する新規 の非イオン性造影剤である。本薬物は, その化学構 造から血漿と等張の浸透圧となっており, 現在臨床 で主に使用されている非イオン性モノマ一型造影剂 に比べて注入時の熱感, 疼痛等を低減するとともに, 中枢神経系, 腎機能, 心機能へ及ぼす影響が少ない。 また，その造影効果はイオへキソールと同等以上で あることが報告されている (Holtz and Goldman, 1987 )。

本論文では，ラットおよびウサギを用いて実施し た iodixanol の生殖発生毒性試験の成績を報告する。

\section{実験材料および方法}

\section{1. 被験物質}

Iodixanol（化学名：A diastereomeric mixture of $5,5^{\prime}$-[(2-hydroxytrimethylene)bis(acetylimino) $]$ bis [N, N'-bis(2, 3-dihydroxypropyl)-2, 4, 6-triiodo-1, 3benzene-dicarboxamide]）はFig.1に示される構造 を有する新規の非イオン性等浸透圧造影剤である。

ラットを用いて実施した 3 試験にはいずれも Nycomed Imaging A.S. 製のバッチ No.FF709209を 使用し，ウサギの試験には同じく Nycomed Imaging A.S. 製のバッチ No.FF907215 およびFF709209を 使用した。

各試験とも，投与液は $10 \mathrm{ml} ハ$ バイアルに $320 \mathrm{mgI} /$ $\mathrm{ml}$ で調製されたものを用い，投与液量を増減させ て所定の投与量を静脈内投与した。対照群には，最 高投与量群と同じ液量の生理食塩液を投与した。<smiles>CC(=O)N(CC(O)CN(C(C)=O)c1c(I)c(C(=O)NCC(O)CO)c(I)c(C(=O)NCC(O)CO)c1I)c1c(I)c(C(=O)NCC(O)CO)c(I)c(C(=O)NCC(O)CO)c1I</smiles>

Fig. 1. Chemical structure of iodixanol. 


\section{2. 使用動物}

ラットの試験には, いずれも Chales River France S.A. より購入した $\mathrm{Crl} ： \mathrm{CD}$ の SPF ラットを 使用した。妊娠前および妊娠初期投与試験には，5 週龄の雄および 7-8 週秢の雌動物を購入し， 6 日 間の順化期間を設け, 雄 (体重範围179-206 g ) は 各群28匹，雌（体重範囲181-211 g ）は各群24匹 に振り分け使用した。胎児の器官形成期投与試験に は, 8-10週龄の交配成立雌ラットを購入し, 妊娠 2 または 3 日に各群24匹に振り分けた（体重範囲 $164-250 \mathrm{~g}$ ，妊娠 2 日)。周産期および授乳期投与 試験には 8-10週㱓の交配成立雌ラットを購入し， 妊娠14日に各群24匹に振り分けた（体重範囲251$372 \mathrm{~g}$, 妊娠14日)。群分けは, 群平均体重がほぼ均 等になるようにコンピュータを用いた層別無作為化 により実施した。

ウサギの試験には，Mollegaards Breeding Centre Ltd. から約 4 ヶ月齢の chbb : HM 系 SPF 交配成立 ウサギ（体重範囲 $1.9-2.9 \mathrm{~kg}$ ) を購入し, 各群 16 匹に振り分けた。群分けは, 交尾成立動物が群間で 均一になるよう, 交配日に交尾成立した順に投与群 およびラック内のケージ配置の割り付けを無作為に 実施した。

\section{3.ラットにおける妊娠前および妊娠初期投与試 験}

先に実施されたラット28日間反復投与毒性試験お よび週 3 回 3 週間間歇投与毒性試験のそれぞれの予 備試験の成績から, 親動物に毒性兆候が認められる と予測される $2.0 \mathrm{gI} / \mathrm{kg} / \mathrm{day}$ を最高投与量に設定し, 中間用量および最低用量は臨床用量の範囲内である 1.0 おび $0.3 \mathrm{gI} / \mathrm{kg} /$ day とした。各群28匹の雄ラッ トには iodixanol の各用量を交配前 9 週間投与した。 このうち投与部位の障害が軽微な雄を各群24匹ずつ 交配用に選抜した。それぞれの雄は同用量の iodixanol を2 週間投与された雌ラットと20日間交配させ た。交配期間中および交尾成立後は雌には妊娠 7 日 まで, 雄には屠殺前日まで継続して投与した。試験 期間中, 一般状態, 体重, 摂餌量および摂水量を記 録した。

交尾が成立した雌は妊娠20日に屠殺, 剖検し, そ
れらの胎児について外表の検査を実施した。雄は交 配相手の雌の剖検後に屠殺, 剖検した。

交配前の雌雄および交配期間終了後の雄動物は吊 り下げ型金属製ケージに雌雄別々（4匹/ケージ） に収容した。交配期間中は雌雄を 1 対 1 で, 妊娠動 物は個別に繁殖用プラスチックケージに収容した。 妊娠動物には床敷きを与えた。飼育環境は, 温度 22 $\pm 3^{\circ} \mathrm{C}$, 湿度 $50 \pm 10 \% ， 8$ 時一 20 時照明の動物室を 使用し，水道水および実験動物用飼料（Labsure, No.1）を自由に摂取させた。

\section{4.ラットにおける胎児の器官形成期投与試験}

先に実施されたラット28日間反復投与毒性試験お よび週 3 回 3 週間間歇投与毒性試験のそれぞれの予 備試験の成績から，親動物に毒性兆候が認められる と予測される $2.0 \mathrm{gI} / \mathrm{kg} / \mathrm{day}$ を最高投与量に設定し, 中間用量および最低用量は臨床用量の範囲内である

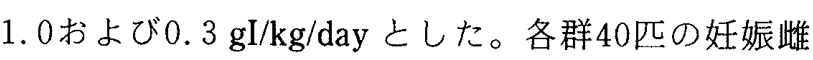
ラットに iodixanol の各用量を妊娠 6 日から17日ま で投与した。試験期間中, 毎日一般状態を観察し， 体重および摂餌量を調べた。各群20匹を妊娠20日に 屠殺, 剖検し, それらの胎児について外表, 内臓お よび骨格の検查を実施した。また，残りの動物を自 然分婏させ, 母動物の哺育行動, 出生児の異常, 体 重, 離乳前の発達（正向反射, 驚愕反射, 空中正向 反射, 瞳孔反射), 離乳後の発達行動検査 (胵開口, 亀頭包皮分割, 加速ローターロッド, Actimat, 1 試行受動的回避）ならびに生殖能力について検查し た。

妊娠期間中の母動物，交配前の F1 および交配期 間終了後の F1 雄動物は吊り下げ型金属製ケージに 雌雄別々（5匹/ケージ）に収容した。分婏させる 動物は個別に, F1 の交配期間中は雌雄を 1 対 1 で, 繁殖用プラスチックケージに収容した。妊娠動物に は床敷きを与えた。飼育環境は, 温度 $23 \pm 5{ }^{\circ} \mathrm{C}$, 湿 度 $56 \pm 12 \% ， 8$ 時一 20 時照明の動物室を使用し，水 道水および実験動物用飼料（Labsure, No.1）を自 由に摂取させた。

\section{5. ウサギにおける胎児の器官形成期投与試験}

先に実施されたラット28日間反復投与毒性試験お よび週 3 回 3 週間間歇投与毒性試験のそれぞれの予 
備試験の成績から，ウサギ母動物においても毒性兆 候が認められると予測される $2.0 \mathrm{gI} / \mathrm{kg} /$ day を最高投 与量に設定し, 中間用量书よび最低用量は臨床用量 の範囲内である 1.0 おび $0.3 \mathrm{gI} / \mathrm{kg} / \mathrm{day}$ とした。各 群16匹の妊娠ウサギに iodixanol の各用量を妊娠 6 日から18日まで投与した。試験期間中, 毎日一般状 態を観察し，体重および摂慨量を調べた。妊娠ウサ ギは妊娠29日に屠殺, 剖検し, それらの胎児につい て外表, 内臓および骨格の検査を実施した。

ウサギは金属製ケージに個別に収容し，温度 $21 \pm$ $2{ }^{\circ} \mathrm{C}$, 湿度 $55.5 \pm 15 \% ， 6$ 時一 18 時照明に設定され た動物室で飼育し， pH 2.5 に調整した水道水およ びウサギ用固形飼料（Altromin 3113）を自由に捸 取させた。

\section{6.ラットにおける周産期および授乳期投与試験}

先に実施されたラット28日間反復投与毒性試験お よび週 3 回 3 週間間歇投与毒性試験のそれぞれの予 備試験の成績から，親動物に毒性兆候が認められる と予測される $2.0 \mathrm{gI} / \mathrm{kg} / \mathrm{day}$ を最高投与量に設定し, 中間用量および最低用量は臨床用量の範囲内である 1.0 およ゙゙0. $3 \mathrm{gI} / \mathrm{kg} / \mathrm{day}$ とした。各群 25 匹の妊娠雌 ラットに iodixanol の各用量を妊娠17日から分婏後 21日まで投与した。試験期間中，毎日一般状態を観 察し，体重および摄慨量を調べた。さらに，全例を 分婏させ, 母動物の哺育行動, 出生児の異常, 体重, 離乳前の発達（正向反射, 驚愕反射, 空中正向反射, 瞳孔反射), 離乳後の発達行動検査（腔開口, 亀頭 包皮分割，加速ローターロッド，Actimat， 1 試行 受動的回避）ならびに生殖能力について検査した。

交配前の雌雄および交配期間終了後の雄動物は吊 り下げ型金属製ケージに雌雄別々（4匹/ケージ） に収容した。交配期間中は雌雄を 1 対 1 で, 妊娠動 物は個別に繁殖用プラスチックケージに収容した。 妊娠動物には床敷きを与えた。飼育環境は, 温度 22 $\pm 3^{\circ} \mathrm{C}$, 湿度 $50 \pm 10 \% ， 8$ 時一 20 時照明の動物室を 使用し，水道水および実験動物用飼料（Labsure, No.1）を自由に摂取させた。

\section{7. 統計処理}

ラットにおける試験では，次のような手法を用い た。親動物の交配能力, 胎児, 出生児の離乳前およ
び出生児の身体発育ならびに行動試験に関するデー 夕については Kruskal-Wallis の検定または Fisher の 直接確率検定を用いて群間差を評価し，同時に Jonckheere 検定を用いて用量依存性を評価した。摄 水量, 摂餌量, 親動物ならびに離乳後の出生児の体 重および腎重量については分散分析の後 Williams の 検定を実施した。

ウサギにおける試験では，次のような手法を用い た。連続変数については Bartlett 検定の結果, 分散 が一様の場合 Dunnett の検定，一様でない場合は Shapiro-Wilk 法により正規性の検定を実施した。そ の結果が正規分布に適合した場合にはStudent $の t$ 検定, 適合しない場合には Kruskal-Wallis の検定に より群間差を調べ，群間に差があればさらにWilcoxonの順位和検定を実施した。また，度数データに ついてはFisher の直接確率検定を用いた。

胎児のデータについては litter 単位で集計し, 評 価した。出生児については, 体重を除く離乳前のデー 夕は litter 単位, 離乳後のデー夕は個別に集計し, 評価した。

\section{実験 結 果}

\section{1.ラットにおける妊娠前および妊娠初期投与試 験}

雌雄ラットの繁殖成績および胎児の観察所見を Table 1 に示した。雙雄ラットの交尾率は全群とも 100\%であり，また妊娠率も 95.8 - 100\%を示し， 投薬の影響は見られなかった。妊娠動物の黄体数お よび着床数にも iodixanol 投与による影響は認めら れなかった。また，胎児死亡率等を含む胎児の検査 所見にも異常は認められなかった。

親動物における一般毒性学的な変化として，1.0 $\mathrm{gl} / \mathrm{kg} /$ day 群の雄では四肢の発赤ならびに四肢およ び顔面の腫脹が投与開始週に 1 または 2 例で 1 日の み観察され，摂水量および腎重量の統計学的に有意 な増加も認められた。これらの変化は同群の雌動物 では観察されなかった。2.0 gI/ $/ \mathrm{kg} / \mathrm{day}$ 群では雌雄の 全例で投与直後に一過性の四肢の発赤が認められ， 透明粘性尿も投与 3 日目頃より観察された。さらに， 
腎重量の有意な増加も雌雄で認められた。また, 雄 動物でのみ四肢の腫脹が投与 6 週まで, 顔面の腫脹 が投与 1 週に観察され，有意な摂水量增加および摂 餌量減少も認められた。

\section{2，ラットにおける胎児の器官形成期投与試験}

Table 2 に胎児の観察所見，母動物の分婏および 出生児に関する成績を示した。胎児の着床後死亡率 は対照群の $7.2 \%$ に対し iodixanol 投与群では $4.9-$ $6.2 \%$ 之同程度の值を示し, 生存胎児数, 胎児体重 にも投薬の影響は見られなかった。形態学的な異常 が0.0-1.7\%の範团で対照群を含む各群に散見され たが，いずれの発現率にも対照群との間に統計学的 に有意な差はなく，胎児に対する催奇形作用は認め られなかった。母動物の分娩・哺育能力, 出生児の 生後発育，身体発育および各種反射ならびに生殖能 力にも投薬の影響は何等認められなかった。

母動物における一般毒性学的な変化として，2.0 $\mathrm{gI} / \mathrm{kg} / \mathrm{day}$ 群の全例で投与後半の 4 日間にわたって 透明粘性尿が認められた以外，投薬に関連した変化 は認められなかった。

\section{3.ウサギにおける胎児の器官形成期投与試験}

Table 3 に胎児の観察所見を示した。胎児の着床 後死亡率が対照群の $3.3 \%$ に対し $9.2-15.7 \%$ と iodixanol 投与群で若干高い值を示したが統計学的に 有意な差はなく, 生存胎児数, 胎児体重, 胎盤重量 にも投薬の影響は見られなかった。また，対照群を 含む各群に形態学的な異常が散見され, 特に腎の暗 色化 (dark kidney) および胆汁澄明 (clear gall-bladder fluid）については，用量に相関した増加傾向が認め られたが，いずれの所見についても統計学的に有意 な差はなく，胎児に対する催奇形作用は認められな かった。

母動物に対する一般毒性学的な観察でも, 投薬に 関連した変化はいずれの群にも認められなかった。

\section{4.ラットにおける周産期および授乳期投与試験}

母動物之出生児に関する検査成績を Table 4 に示 した。母動物の妊娠期間，哺育能力に投薬の影響は 認められず，出生児の離乳までの生存率 (97.2$98.8 \%)$, 身体発達, 各種反射, 生殖能力および F2 児の出生率, 離乳率にも影響は認められなかった。

一般毒性学的な変化として, $1.0 \mathrm{gI} / \mathrm{kg} /$ day 以上の 用量群の母動物に統計学的に有意な腎重量の増加 が，2.0 gI/kg/day 群ではさらに投与直後に一過性の 耳介発赤が妊娠19日より投薬終了まで認められた。

Table 1. Study with dosing prior to and in the early stages of pregnancy in rats.

\begin{tabular}{lcccc}
\hline \multicolumn{1}{c}{ Dose (gI/kg/day) } & 0 & 0.3 & 1.0 & 2.0 \\
\hline No. of males & 24 & 24 & 24 & 24 \\
No. of females & 24 & 24 & 24 & 24 \\
Copulation index (\%) & 100.0 & 100.0 & 100.0 & 100.0 \\
Pregnancy index (\%) & 100.0 & 100.0 & 95.8 & 95.8 \\
No. of corpora lutea (mean) & 17.8 & 18.9 & 17.6 & 17.4 \\
No. of implants (mean) & 16.7 & 17.2 & 16.6 & 16.4 \\
Pre-implantation loss (\%) & 5.8 & 7.7 & 5.5 & 5.7 \\
Post-implantation loss (\%) & 5.3 & 4.8 & 6.2 & 6.2 \\
No. of live fetuses (mean) & 15.8 & 16.4 & 15.6 & 15.4 \\
Body weight of live fetuses (mean, g) & 3.71 & 3.63 & 3.64 & 3.71 \\
Fetuses with external anomalies (\%) & 0.3 a) & 0.0 & 0.0 & $2.2^{\text {b) }}$ \\
\hline
\end{tabular}

pre-implantation loss $(\%)=\frac{\text { (number of corpora lutea }- \text { number of implants) }}{\text { number of corpora lutea }} \times 100$

post-implantation loss $(\%)=\frac{\text { (number of implants }- \text { number of live fetus })}{\text { number of implants }} \times 100$

a : umbilical hernia, $\quad$ b : subcutaneous oedema 
Table 2. Teratological study in rats.

\begin{tabular}{|c|c|c|c|c|}
\hline Dose $(\mathrm{gI} / \mathrm{kg} /$ day $)$ & 0 & 0.3 & 1.0 & 2.0 \\
\hline \multicolumn{5}{|l|}{ Caesarean section } \\
\hline No. of dams examined & 20 & 20 & 20 & 20 \\
\hline No. of corpora lutea (mean) & 16.8 & 16.0 & 16.0 & 17.1 \\
\hline No. of implants (mean) & 14.1 & 13.6 & 12.4 & 15.3 \\
\hline Post-implantation loss (\%) & 7.2 & 6.0 & 6.2 & 4.9 \\
\hline No. of live fetuses (mean) & 13.1 & 12.8 & 11.6 & 14.6 \\
\hline Body weight of live fetuses (mean, g) & 3.93 & 3.82 & 4.01 & 3.93 \\
\hline Fetuses with external anomalies (\%) & $1.4^{\text {a) }}$ & $0.9^{b)}$ & $1.7^{\mathrm{c})}$ & $1.4^{\mathrm{d})}$ \\
\hline Fetuses with visceral anomalies (\%) & $1.3^{\mathrm{e})}$ & 0.0 & $0.8^{f)}$ & 0.0 \\
\hline Fetuses with skeletal anomalies (\%) & 0.0 & $1.5^{\mathrm{g})}$ & $0.8^{\mathrm{h})}$ & $0.7^{\mathrm{i})}$ \\
\hline \multicolumn{5}{|l|}{ Normal delivery } \\
\hline No. of dams examined & 16 & 16 & 19 & 15 \\
\hline Length of gestation (mean, day) & 21.6 & 21.5 & 21.6 & 21.6 \\
\hline No. of pups born alive (mean) & 13.2 & 13.2 & 14.1 & 13.3 \\
\hline Delivery index $(\%)$ & 100.0 & 93.8 & 100.0 & 100.0 \\
\hline Birth index $(\%)$ & 92.6 & 89.6 & 93.1 & 88.9 \\
\hline Weaning index (days $0-21, \%$ ) & 97.2 & 97.0 & 99.6 & 97.8 \\
\hline Physical development & - & - & - & - \\
\hline Behavior & - & - & - & - \\
\hline \multicolumn{5}{|l|}{ Reproductive performance of F1 } \\
\hline No. of pairs mated & 10 & 9 & 10 & 10 \\
\hline Copulation index (\%) & 100.0 & 88.9 & 100.0 & 100.0 \\
\hline Delivery index $(\%)$ & 100.0 & 100.0 & 100.0 & 100.0 \\
\hline Birth index of F2 (\%) & 91.6 & 95.1 & 94.3 & 95.4 \\
\hline No. of $F 2$ pups born alive (\%) & 15.1 & 14.9 & 16.3 & 14.6 \\
\hline
\end{tabular}

- : No remarkable changes $a:$ dwarf, edema $b:$ dwarf, misshapen jaw $c:$ dwarf, misshapen jaw $\mathrm{d}$ : dwarf, forelimb flexure e : anophtalmia, complex anomaly (intrathoracic edema, cardiovascular abnormalities, and enlarged and vacuollated adrenal glands) $\mathrm{f}$ : diaphragmatic hernia $\mathrm{g}$ : complex anomaly (anomalous basal cranial bones, scapulae, sternebrae and lumber vertebral centra and wavy/thickened ribs), wavy/thickened ribs $\mathrm{h}$ : grossly abnormal head $\mathrm{i}$ : thickened ribs 
Table 3. Teratological study in rabbits.

\begin{tabular}{lcccc}
\hline \multicolumn{1}{c}{ Dose (gI/kg/day) } & 0 & 0.3 & 1.0 & 2.0 \\
\hline No. of dams examined & 16 & 16 & 16 & 16 \\
No. of corpora lutea (mean) & 6.9 & 7.9 & 7.3 & 6.9 \\
No. of implants (mean) & 5.5 & 6.6 & 6.2 & 5.7 \\
No. of live fetuses (mean) & 5.3 & 5.5 & 5.5 & 5.1 \\
Post-implantation loss (\%) & 3.3 & 15.7 & 14.5 & 9.2 \\
Body weight of live fetuses (mean, g) & 39.76 & 39.28 & 39.06 & 41.80 \\
Placental weight (mean, g) & 24.41 & 25.84 & 25.49 & 23.31 \\
Fetuses with external anomalies (\%) & & & & \\
$\quad$ Haemorrhages at jugular vein & 8.0 & 2.8 & 1.0 & 1.0 \\
Fetuses with visceral anomalies (\%) & & & & \\
$\quad$ Dark kidney & 2.7 & 8.6 & 9.1 & 17.7 \\
$\quad$ Haemorrhages in thymus $\quad 8.0$ & 6.0 & 7.9 & 2.3 \\
$\quad$ Clear gallbladder fluid & 0.0 & 0.9 & 3.6 & 5.5 \\
Fetuses with skeletal anomalies (\%) & & & & \\
$\quad$ 12th rib(s) small, short or shaped pointed & 24.2 & 22.7 & 18.9 & 15.1 \\
\hline
\end{tabular}

Table 4. Perinatal and postnatal study in rats.

\begin{tabular}{lcccc}
\hline \hline Dose (gI/kg/day) & 0 & 0.3 & 1.0 & 2.0 \\
\hline No. of dams examined & 25 & 24 & 24 & 24 \\
Length of gestation (mean, days) & 21.4 & 21.1 & 21.3 & 21.1 \\
No. of pups born alive (mean) & 12.8 & 13.5 & 12.6 & 12.6 \\
Delivery index (\%) & 100.0 & 100.0 & 100.0 & 100.0 \\
Birth index (\%) & 91.7 & 94.5 & 92.9 & 89.6 \\
Weaning index (days 0-21, \%) & 97.2 & 98.8 & 98.8 & 98.1 \\
Physical development & - & - & - & - \\
Behavior & - & - & - & - \\
& & & & \\
Reproductive performance of F1 & & & & 20 \\
$\quad$ No. of pairs mated & 20 & 20 & 100.0 & 100.0 \\
Copulation index (\%) & 95.0 & 100.0 & 100.0 & 100.0 \\
Delivery index (\%) & 100.0 & 100.0 & 91.7 & 94.9 \\
Birth index of F2 (\%) & 93.5 & 94.1 & 15.3 & 15.9 \\
No. of F2 pups born alive & 15.3 & 16.1 & & \\
\hline
\end{tabular}

- : No remarkable changes 


\section{考察}

ラットにおける妊娠前および妊娠初期投与試験で は, 雄動物の $1.0 \mathrm{gl} / \mathrm{kg} /$ day 以上の用量群で一過性の 四肢の発赤, 四肢および顔面の腫脹, 椇水量および 腎重量の増加が認められ，2.0 gI/ $/ \mathrm{kg} /$ day 群ではさら に透明粘性尿および摂餌量減少が認められた。また， 雌動物では $2.0 \mathrm{gI} / \mathrm{kg} / \mathrm{day}$ 群で一過性の四肢の発赤, 透明粘性尿および腎重量の増加が認められたが, 雌 雄動物の生殖能力には投薬の影響は認められなかっ た。四肢および顔面の腫脹は，iodixanol と同じく 非イオン性ダイマー型造影剤である iotrolan の急性 毒性試験（真田ら，1986）および iodixanol のラッ 卜における単回毒性試験（源田, 大野，1995）でも 認められており，薬剤の大量投与による影響である と考えられている。また，四肢の発赤も投薬に関連 していると考えられるが，いずれも一過性の変化で あり毒性学的意義は少ないものと考えられた。また， 腎重量の増加は iodixanol が腎臓に一時的に貯留し たために起こったものであり，透明粘性尿も iodixanol が未変化のまま排出されているために観察され た所見であると考えられることから，薬物の作用に よる毒性変化ではないと考えられる。Iotrolan の妊 娠前および妊娠初期投与試験（児玉ら，1986）では, 掑餌量の減少, 着床数と生存胎児数の減少が認めら れているが, 本試験では $2.0 \mathrm{gI} / \mathrm{kg}$ 群で摂餌量の減 少が見られたものの, 全群を通じて着床への影響な らびに胎児致死作用は認められなかった。以上のこ とから, 本試験における雄動物の一般毒性学的無毒 性量は $0.3 \mathrm{gI} / \mathrm{kg} / \mathrm{day}$, 生殖機能に対する無毒性量は $2.0 \mathrm{gI} / \mathrm{kg} / \mathrm{day}$ であると考えられた。雌動物および胎 児に対する無毒性量は $2.0 \mathrm{gI} / \mathrm{kg} / \mathrm{day}$ であると考えら れた。

ラットにおける胎児の器官形成期投与試験では, $2.0 \mathrm{gI} / \mathrm{kg} / \mathrm{day}$ 群の母動物に透明粘性尿が認められた のみで, その他の観察項目には投薬に関連した変化 は認められなかった。また, 胎児に対する催奇形作 用や出生児の生後発育にも投薬の影響は全く認めら れなかった。Iotrolan の胎児器官形成期投与試験 (児
玉ら，1986）でも，胎児に対する影響は報告されて いないが，母動物に摂餌量の減少が認められており， 本試験とは母動物に対する影響で異なった結果が得 られている。母動物で観察された透明粘性尿には毒 性学的意味は少ないと考えられることから，母動物， 胎児ならびに出生児に対する無毒性量はいずれも $2.0 \mathrm{gI} / \mathrm{kg} /$ day であると考えられた。

ウサギにおける胎児の器官形成期投与試験では, 明らかに投薬に起因すると考えられる変化は母動物 において認められなかうた。胎児の内臓異常として， 腎の暗色化（dark kidney）および胆汁澄明（clear gall-bladder fluid）が用量相関的に増加したが，い ずれの発現率にも統計学的に有意な差は認められな かった。さらに，腎の暗色化については1匹しか胎 児がいない腹で観察されたために見かけ上発現率が 増加したものであり, 胆汁澄明についても各群の 1 または 2 腹でのみ観察されていることから，投薬と の関連はないと考えられる。以上の結果から，母動 物および胎児に対する無毒性量はいずれも $2.0 \mathrm{gI} /$ kg/dayであると考えられた。

ラットにおける周産期および授乳期投与試験で は， $1.0 \mathrm{gI} / \mathrm{kg} /$ day 以上の用量群で腎重量の増加が， $2.0 \mathrm{gI} / \mathrm{kg} / \mathrm{day}$ 群ではさらに一過性の耳介発赤が認め られたが，母動物の児を哺育する能力に投薬の影響 は認められなかった。母動物に見られた腎重量の増 加はiodixanol が腎に貯留したために起こった現象 であると考えられ，耳介発赤についても一過性の変 化であることから，いずれの所見も毒性学的意味は 少ないと考えられた。以上のことから，母動物なら びに出生児に対する無毒性量はともに $2.0 \mathrm{gI} / \mathrm{kg} / \mathrm{day}$ であると考えられた。なお，iotrolanの周産期およ び授乳期投与試験（児玉ら，1986）においても，本 試験上同様，母動物および出生児に対し投薬の影響 は認められていない。

\section{要約}

Iodixanol の生殖発生毒性をラットおよびウサギ を用いて実施した。

ラットにおける妊娠前および妊娠初期投与試験で 
は, 雄動物の $1.0 \mathrm{gl} / \mathrm{kg} /$ day 以上の用量群で四肢およ び顔面の腫脤, 摂水量増加が認められ, $2.0 \mathrm{gI} / \mathrm{kg} /$ day 群ではさらに摂餌量の減少が認められたが, 雌 動物には毒性兆候は見ら扎なかった。また，雌雄動 物の生殖能力にも投薬の影響は認められなかった。 以上のことから, 本試験における雄動物の一般毒性 学的無毒性量は $0.3 \mathrm{gI} / \mathrm{kg} / \mathrm{day}$, 生殖機能に対する無

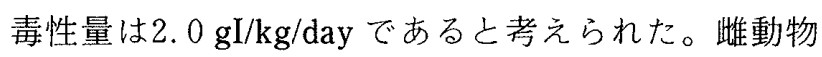
および胎児に対する無毒性量は2.0 gl $/ \mathrm{kg} /$ day である と考えられた。ラットにおける胎児の器官形成期投 与試験では，母動物に薬物の毒性を示す変化は認め られず，胎児ならびに出生児の生後発育にも投薬に 関連した変化は認めら机なかった。以上のことから， 母動物, 胎児ならびに出生児に対する無毒性量はい ずれも $2.0 \mathrm{gI} / \mathrm{kg} / \mathrm{day}$ であると考えられた。ウサギに おける胎児の器官形成期投与試験では, 明らかに投 薬に起因すると考えられる変化は母動物および胎児 のいずれにも認められなかったことから，母動物お よび胎児に対する無毒性量はいずれも $2.0 \mathrm{gI} / \mathrm{kg} / \mathrm{day}$ であると考えられた。ラットにおける周産期および 授乳期投与試験では，明らかに投薬に起因すると考 えられる変化は母動物および出生児のいずれにも認 められなかった。以上のことから，母動物ならびに
出生児に対する無毒性量はともに $2.0 \mathrm{gI} / \mathrm{kg} /$ day であ ると考えられた。

\section{文献}

源田百合, 山村久, 高橋裕嗣, 石島奈美, 古濱和久, 柿畑 耕司, 大野広志, 野村護 (1995)：新規非イオン性等 浸透圧造影剤i iodixanol のマウス, ラットおよびサルに お ける静脈内単回投与毒性. J. Toxicol. Sci., 20, Suppi. I, 47-66.

Holtz, E. and Goldman, K. (1987) : Experimental urography with new non-ionic dimeric and monometric contrast agents. Acta Radiol. Suppl., 370, 49-55.

児玉直已, 坪田邦広, 加藤和恵, 占部圭子, 中尾寿夫 (1986)： Iotrolan の生殖試験(1)ーラットの妊娠前および娃娠初 期投与試験一. 日獨医報, 31(2)，304-315.

児玉直己, 坪田邦広, 加藤和恵, 占部圭子, 中尾寿夫 (1986): Iotrolan の生殖試験( 2$)$ - ラットの器官形成期投与試験 一. 日獨医報, 31(2)，316-331。

児玉直己, 坪田邦広, 加藤和惠, 占部圭子, 中尾寿夫 (1986)： Iotrolan の生殖試験(3) 一ラットの周産期および授乳期 投与試験一. 日獨医報, 31(2), 332-346.

真田緑, 原麻奈子, 三輪美貴子, 中尾寿夫 (1986)：Iotrolan の毒性研究(1)ーラット, マウスにおける急性毒性 試験一。日獨医報, 31(2), 283-286. 